\title{
Effect of Manganese Content on the Fabrication of Porous Anodic Alumina
}

\author{
C. H. Voon, M. N. Derman, and U. Hashim \\ Institute of Nano Electronic Engineering, Universiti Malaysia Perlis, Seriab, Kangar, 01000 Perlis, Malaysia \\ Correspondence should be addressed to C. H. Voon, david_voon@hotmail.com
}

Received 29 February 2012; Revised 26 April 2012; Accepted 3 May 2012

Academic Editor: Fengxi Chen

Copyright () 2012 C. H. Voon et al. This is an open access article distributed under the Creative Commons Attribution License, which permits unrestricted use, distribution, and reproduction in any medium, provided the original work is properly cited.

The influence of manganese content on the formation of well-ordered porous anodic alumina was studied. Porous anodic alumina has been produced on aluminium substrate of different manganese content by single-step anodizing at $50 \mathrm{~V}$ in $0.3 \mathrm{M}$ oxalic acid at $15^{\circ} \mathrm{C}$ for 60 minutes. The well-ordered pore and cell structure was revealed by subjecting the porous anodic alumina to oxide dissolution treatment in a mixture of chromic acid and phosphoric acid. It was found that the manganese content above $1 \mathrm{wt} \%$ impaired the regularity of the cell and pore structure significantly, which can be attributed to the presence of secondary phases in the starting material with manganese content above $1 \mathrm{wt} \%$. The pore diameter and interpore distance decreased with the addition of manganese into the substrates. The time variation of current density and the thickness of porous anodic alumina also decreased as a function of the manganese content in the substrates.

\section{Introduction}

Porous anodic alumina (PAA) is a self-organizing porous material. After the confirmation of the classical cell model proposed by Keller et al. [1], PAA has attracted enormous attraction as inexpensive template for the fabrication of various nanostructured materials without the need of costly and complex lithographic techniques [2-6]. PAA is a suitable template for the synthesis of nanostructured materials because its cell parameters such as pore diameter, interpore distance, and pore depth can be controlled easily by varying anodizing conditions $[7,8]$. The fabrication of nanostructured materials by template synthesis method employs wellordered PAA because well-ordered PAA provides regular pore shape and narrow distribution of specific pore diameter and interpore distance for the synthesis of nanostructured materials of uniform dimensions. Since the properties of nanostructured materials are significantly influenced by the dimensions, it is important to synthesis nanostructured materials of uniform dimensions $[6,9,10]$.

In order to fabricate well-ordered PAA, various approaches were proposed. First, well-ordered PAA was realized by Masuda and Fukuda in 1995 [11]. They employed a twostep anodizing method for the synthesis of well-ordered PAA.
Since then, owing to the commercial potential and scientific significance, there has been an ongoing research effort towards the fabrication of well-ordered PAA. prepatterning method such as imprint lithography [12-14], focused ion beam lithography [15], and electron beam lithography [16] were also developed for the fabrication of the well-ordered PAA. These methods involved the formation of indented concave periodic patterns on the aluminium substrates prior to the anodizing process. These patterns served as guide for the nucleation and growth of well-ordered PAA. Besides, high field anodizing was also proposed as an alternative for the synthesis of well-ordered PAA [17]. Critical high anodizing potential which is the anodizing potential required to induce high current density while preventing local current density concentration on the aluminium surface was applied during the high field anodizing.

Although many techniques for the synthesis of well ordered PAA were reported, these techniques employed high-purity aluminium (99.99\%) substrate as a starting material. The cost of high-purity aluminium is high and it has limited the commercial potential and applications of well-ordered PAA in the large-scale template synthesis of nanostructured materials. Therefore there is always a need 
to find an alternative of high-purity aluminium substrate to widen the applications of PAA. Comparing to high-purity aluminium, the costs of aluminium alloys are relatively low. Thus, anodizing of aluminium alloys is a good alternative to obtain low-cost template for the synthesis of nanostructured materials. However, due to the complexity of the anodizing of aluminium alloys, there are only a few reports on the fabrication of PAA film from aluminium alloy and most of these studies are emphasized on the commercially available aluminium alloys [18-21]. Commercially available aluminium alloys normally consist of $\mathrm{Si}, \mathrm{Fe}, \mathrm{Mg}, \mathrm{Mn}$, and $\mathrm{Cu}$ as alloying elements. These alloying elements have different behaviours during the anodizing process. They may promote or hinder the fabrication of well-ordered PAA. Furthermore, these alloying elements may react among each other before or during the anodizing process. The study of synthesis of PAA from commercially available aluminium alloy is therefore difficult to be analyzed and concluded.

Manganese (Mn) is one of the major alloying elements used in aluminium alloys. It is added up to two percent to enhance the corrosion resistance of aluminium alloys, especially in $3 \mathrm{xxx}$ series. To the best of our knowledge, there is no study conducted on the effect of $\mathrm{Mn}$ in the synthesis of PAA. Limited study was reported on the synthesis of barrier type anodic alumina from Al-Mn alloys [22]. There is a growing interest in the development of economic alternative for the synthesis of well-ordered PAA. The cost of large-scale production of nanostructured materials can be significantly reduced when the well-ordered PAA is fabricated from aluminium alloys instead of expensive-highpurity aluminium. Thus, the purpose of this study is to investigate the effect of addition of $\mathrm{Mn}$ into aluminium substrate on the fabrication of well-ordered PAA. The results of this study are important in the analysis of anodizing of commercially available aluminium alloy and in determining the suitable alternative of the high-purity aluminium for the fabrication of well-ordered PAA. In this context, we report a comparative study of the characteristic parameters of well-ordered PAA fabricated from high-purity aluminium (99.99\%) and Al-Mn alloy (up to $2 \%$ of Mn) under the same operating conditions.

\section{Experimental}

For high-purity (99.99\%) aluminium samples, about 150 gram of aluminium pellets (99.99\%) were weighted and melted at $850^{\circ} \mathrm{C}$. The molten aluminium was then poured into a $25 \mathrm{~mm}$ diameter stainless steel cylindrical mould. To fabricate substrate of different Mn content, high-purity (99.99\%) aluminium pellets and $\mathrm{Al}-20 \mathrm{wt} \% \mathrm{Mn}$ master alloys of respective mass were cast in the same manner as the high-purity aluminium samples. Substrates of $4 \mathrm{~mm}$ in thickness were sectioned from respective casting products. To remove the residual stress in the substrates that was formed during the sectioning process, the substrates were annealed at $450^{\circ} \mathrm{C}$ for four hours and annealed in furnace to room temperature.

All substrates were grinded by using silicon-carbide paper up to 2000 grit to remove scratches formed on the substrate surfaces during sectioning process. The substrates were then polished by using alumina polishing suspension of $6 \mu \mathrm{m}, 1 \mu \mathrm{m}$, and $0.05 \mu \mathrm{m}$ successively to achieve mirrorlike surface. Substrates were degreased by dipping in a stirred ethanol and rinsed with deionised water. Microstructures of the polished substrates were captured by using optical microscope. The mass of the substrates before subjecting to anodizing were weighted and recorded.

Substrates were then anodized under the same operating conditions. Lead plate was used as cathode. The distance between the lead cathode and aluminium anode was $40 \mathrm{~mm}$. Anodizing was performed at constant voltage for a sufficient time for the development of steady-state morphology within the film. Anodizing was conducted in $0.3 \mathrm{M}$ oxalic acid of $15^{\circ} \mathrm{C}$ at constant voltage of $50 \mathrm{~V}$. The temperature variance was controlled within $\pm 0.5^{\circ} \mathrm{C}$. Current density-time curve was recorded during the anodizing process. The anodized substrates were rinsed with flowing ethanol followed by deionised water and dried.

Three samples of $5 \mathrm{~mm} \times 5 \mathrm{~mm}$ in area each were sectioned from each anodized substrate. The cross sections of the substrates were observed under SEM. The thickness of the PAA film was measured by using software JEOL SmileView version 2.1. The steady-state structure of PAA beneath the initially formed irregular structure was revealed by oxide dissolution treatment. A mixture of chromic acid and phosphoric acid was prepared from $20 \mathrm{~g}$ of chromic acid and $35 \mathrm{ml}$ of $85 \mathrm{wt} \%$ phosphoric acid in $1000 \mathrm{~mL}$ of distilled water. One anodized substrate of $5 \mathrm{~mm} \times 5 \mathrm{~mm}$ in area was then subjected to oxide dissolution treatment in a stirred mixture of chromic acid and phosphoric acid at 70$80^{\circ} \mathrm{C}$ for eight hours. The substrate was rinsed thoroughly with ethanol followed by distilled water and dried. The morphology of the treated PAA was observed under SEM. Pore diameter and interpore distance of PAA were measured by using software JEOL SmileView version 2.1.

To measure the mass of oxide film formed, same solution which was used for oxide dissolution treatment was prepared. The mass of the anodized substrates of $5 \mathrm{~mm} \times 5 \mathrm{~mm}$ in area before subjecting to dissolution process was recorded. The anodized substrate was then stirred in the mixture at $70-80^{\circ} \mathrm{C}$ for 8 hours. The substrate was rinsed thoroughly with ethanol and distilled water and dried. The weight of the respective substrate was recorded. The difference of the weight of substrate before and after subjecting to the oxide dissolution treatment is the mass of the PAA, $m_{p}$. The current efficiencies of the anodizing of substrate of different $\mathrm{Mn}$ content were calculated based on the reported literature [23]. The mass of aluminium metal converted to oxide, $\left(m_{\mathrm{Al}}\right)_{\eta}$ was related to mass balance over the anodized sample in

$$
m_{p}=\left(m_{\mathrm{Al}}\right)_{\eta}+\left(m_{f}-m_{i}\right)
$$

in which $m_{i}$ and $m_{f}$ are the masses of the anodized sample before and after anodizing and these values were recorded previously. Current efficiency is defined as the ratio of the actual amount of current used for oxide formation relative to the total current passed. Mass of oxide formed, $m_{p}$, was determined from the difference of the mass of 


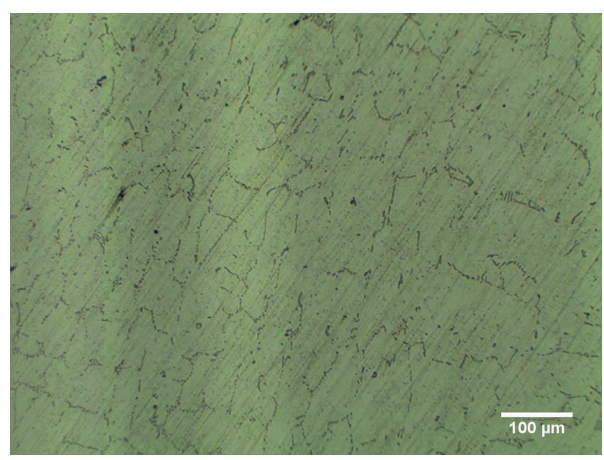

(a)

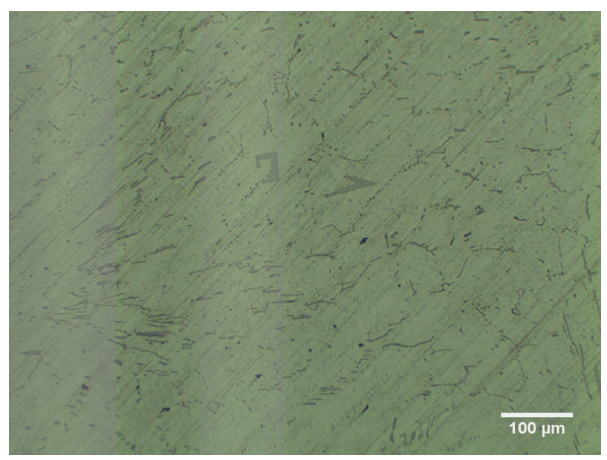

(c)

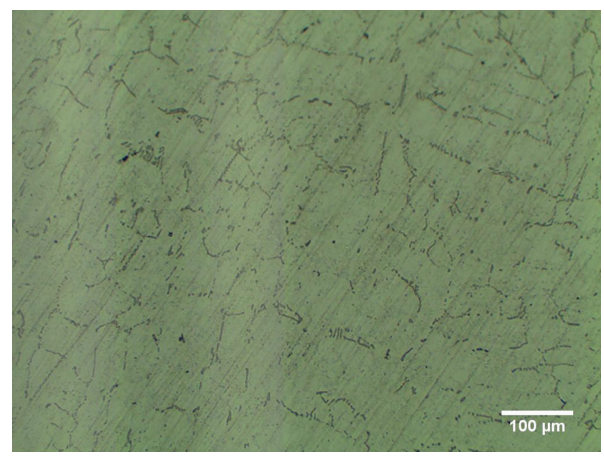

(b)

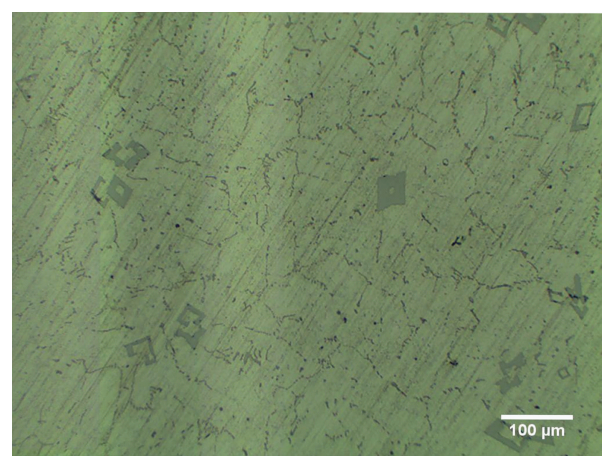

(d)

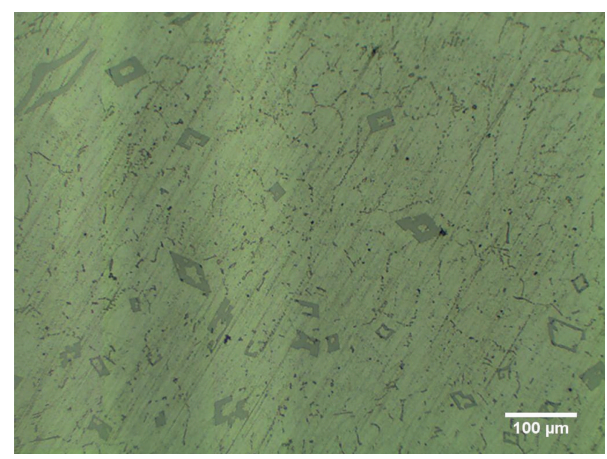

(e)

Figure 1: Microstructure of substrates prior subjecting to anodizing (a) high-purity aluminium, aluminium with (b) 0.5 wt $\%$ Mn, (c) $1.0 \mathrm{wt} \% \mathrm{Mn}$, (d) $1.5 \mathrm{wt} \% \mathrm{Mn}$, and (e) $2.0 \mathrm{wt} \%$ Mn, respectively.

anodized sample before and after oxide dissolution. By fitting experimental values of $m_{p}, m_{f}$, and $m_{i}$ into $(1),\left(m_{\mathrm{Al}}\right)_{\eta}$ was determined. The mass of aluminium metal converted to oxide with current efficiency, $\eta=100 \%$, was determined by using

$$
\left(m_{\mathrm{Al}}\right)_{\eta}=\eta \frac{2 M_{\mathrm{Al}_{3}} A_{t} i t}{z F}
$$

in which $M_{\mathrm{Al}}$ is the molecular weight of aluminium or aluminium alloy, At is the anodized area, $i$ is the current density, $t$ is the anodizing duration, $z$ is the number of electron involved in the reaction, $F$ is the Faraday constant, and $\left(m_{\mathrm{Al}}\right)_{\eta=100}$ is the mass of aluminium or aluminium alloy calculated using equation with current efficiency, $\eta=100 \%$.
The current efficiency, $\eta$, was then determined by

$$
\eta=\frac{\left(m_{\mathrm{Al}}\right)_{\eta}}{\left(m_{\mathrm{Al}}\right)_{\eta=100}} .
$$

\section{Result and Discussion}

Figure 1 shows the microstructures of the substrates before subjecting to anodizing. We observed from Figures 1(a) and (b) that high-purity aluminium and $\mathrm{Al}-0.5 \mathrm{wt} \% \mathrm{Mn}$ have similar homogeneous grain microstructures. No secondary phase is present in these substrates. Spot analysis by element dispersive $\mathrm{X}$ ray spectroscopy (EDX) in Figure 2(a) shows that this phase is aluminium rich and the amount of manganese is too little to be detected. However, for substrate with $\mathrm{Mn}$ content range from $1.0 \mathrm{wt} \%$ to $2.0 \mathrm{wt} \%$, 


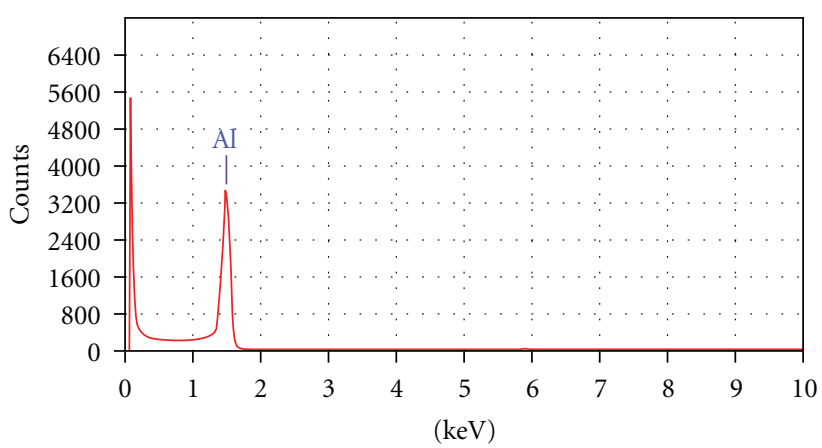

(a)

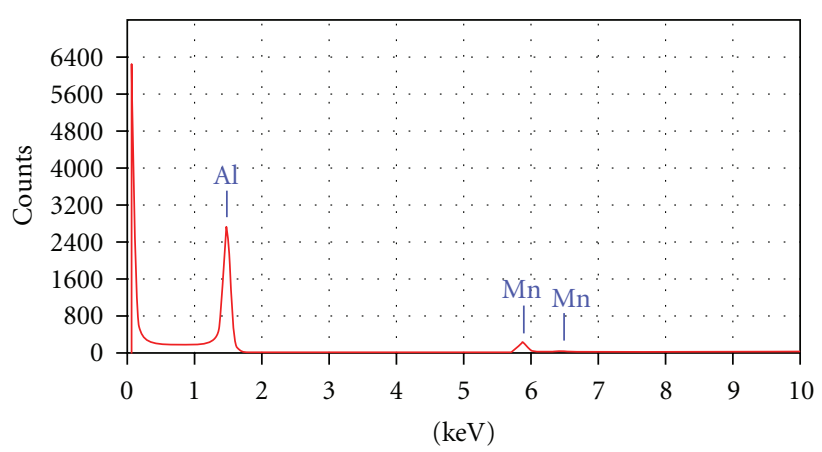

(b)

FIgURE 2: Energy dispersive X-ray spectroscopy spot analysis spectra for (a) bright grain structure and (b) dark precipitates.

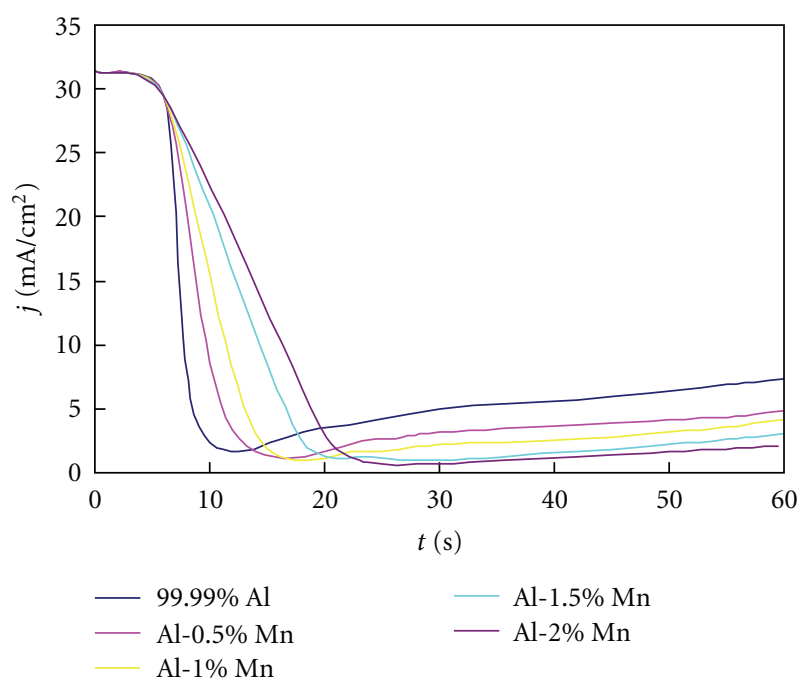

FIGURE 3: The current density as a function of time during anodizing.

we observed two phase microstructures. Dark-precipitated phases are distributed in the lighter matrix phase. The size and occurrence of precipitated phase increase when the $\mathrm{Mn}$ content in the substrates increases from $1.0 \mathrm{wt} \%$ to $2.0 \mathrm{wt} \%$. EDX spot analyses in Figure 2(b) reveal that these precipitated phases consist of both $\mathrm{Al}$ and $\mathrm{Mn}$ species. By referring to phase diagram, the $\mathrm{Mn}$ containing phase is suggested to be $\mathrm{MnAl}_{6}$ compound [24].

Figure 3 shows the variation of current density as a function of time for aluminium substrate of different Mn content. The plots of all substrates shared similar features and exhibited a typical manner of anodizing of aluminium in oxalic acid [25]. At the commencement of anodizing, there is a current surge. This current density surge is followed by a rapid fall in current density to a minimum. The current density then increases slowly to a steady-state value and maintains at this value for the rest of the anodizing time. At the initial stage, due to the low-electrical resistance of the clean surface, the current density increases rapidly. When reaches the peak, the thickening of nonconductive barrier type alumina occurs and the current density drops rapidly to a minimum value. However, the thickness of the barrier type alumina film is not uniform and pores exist on the surface of the film. The thickness of the alumina is lower at these pores and the electric field will concentrate at these pores. Fieldassisted dissolution mechanism of the oxide film commences and the field electric resistance decreases with the emergence of the pores and the current density increases subsequently. The steady-state current density is reached when the rate of oxide dissolution at the base of the pores equals the rate of oxide formation at the metal/oxide interface, indicating the finish of pore-organizing process [26].

Since anodizing current density is mainly dependant on the ionic current, the current density is considered an indicator of the growth rate of alumina during the anodizing process. Although the plots in Figure 3 show similar shapes, the overall anodizing current density decreased as a function of $\mathrm{Mn}$ content. This indicated the $\mathrm{Mn}$ content in the substrate impedes the formation of the alumina film. Furthermore, the addition of Mn into the substrate has delayed the occurrence of lowest point of current density during the anodizing process. This means that the addition of Mn into the substrate has retarded the pore nucleation and pore organization process during the anodizing process. As a consequence, the steady state current density was achieved within a longer anodizing duration. For Al-Mn alloys, when the anodizing was started, preferential oxidation of aluminium occurred and enrichment of Mn species in the form of thin layer formed beneath the PAA [22]. We believed that the enrichment of Mn species beneath the anodic film lead to the reduced availability of $\mathrm{Al}$ for oxidation and subsequently reduced the recorded current density. As pore nucleation only started when a certain thickness of PAA film is reached, the reduced $\mathrm{Al}$ availability retarded the pore nucleation and pore organization; therefore the minimum and maximum values of current density were reached within a longer duration.

As the anodizing behaviours are affected by the Mn content of the substrate, considerable modifications of microstructure of the PAA were expected. Figure 4 shows the SEM images of PAA film after the removal of initially formed irregular PAA by oxide dissolution treatment. Generally, as the Mn content in the aluminium 


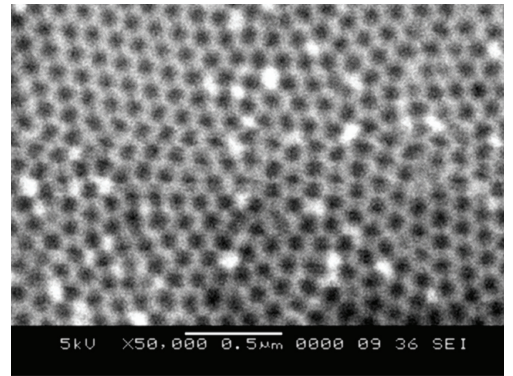

(a)

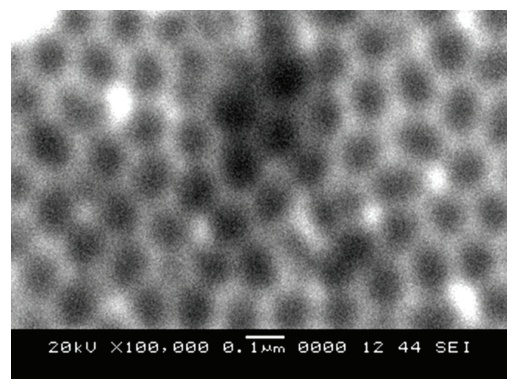

(d)

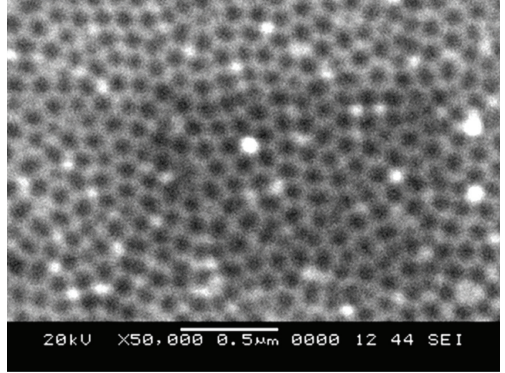

(b)

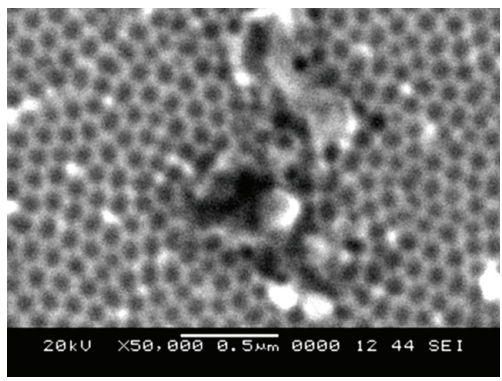

(e)

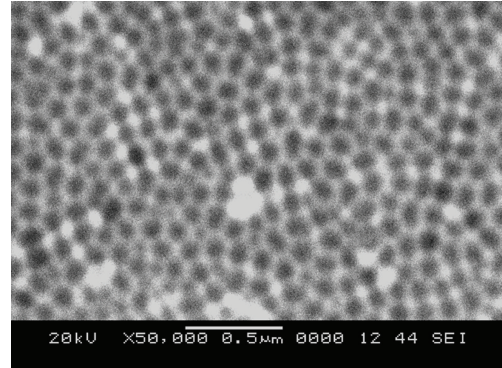

(c)

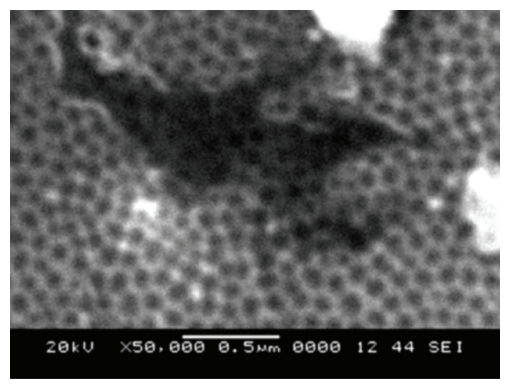

(f)

Figure 4: Top view SEM images of anodized substrate of (a) high-purity aluminium, (b) Al-0.5 wt\% Mn, (c) and (d) Al-1.0 wt\% Mn, (e) Al- $1.5 \mathrm{wt} \% \mathrm{Mn}$, and (f) Al-2.0 wt $\% \mathrm{Mn}$.

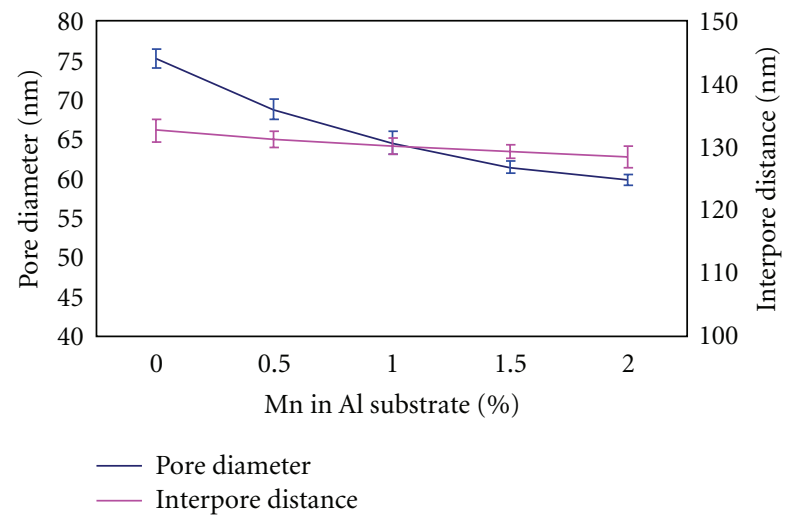

FIGURE 5: Variation of pore diameter and interpore distance of PAA as a function of Mn content.

substrates increases, the regularity of the pores arrangement decreases. We observed that the PAA formed on the highpurity-aluminium substrate exhibits a nearly ideal hexagonal arrangement of pores, as shown in Figure 4(a). The pores are uniform in both shape and size. As the Mn content in the aluminium substrate increases up to $0.5 \mathrm{wt} \%$ and $1.0 \mathrm{wt} \%$ in Figures 4(b) and 4(c), respectively, the hexagonal arrangements of pores are still retained. However, the shapes of pores formed in the Al-1.0\% Mn substrate are slightly elongated and turned into oval shape. Furthermore, pits are found on the PAA for Al-1.0\% Mn substrate at higher magnification, as shown in Figure 4(d). The pores around the pits are deflected and pressed into oval shape. We believed that these pits are attributed to the intermetallic particles that are embedded in the starting aluminium substrates. These intermetallic particles are either not oxidized or only partially oxidized during the anodizing process and incorporated into the PAA. These intermetallic particles are removed during the oxide dissolution treatment and as a result, pits are formed at these locations. As a result of nonuniform oxidation rates and volume expansion between the intermetallic particles and the aluminium alloy matrix, the pores around the intermetallic particles are deformed. Furthermore, pores may stop to grow when the reaction front reaches the intermetallic particles. As the reaction front passed the intermetallic particles, the aluminium alloy matrix will be anodized again. Due to the tendency of the pores to grow perpendicular to the surface, the pores formed beneath the intermetallic particles are deviated [27]. As the Mn content in the substrates further increased to $2.0 \mathrm{wt} \%$, the hexagonal arrangements of the pores are disturbed to a greater extend. In addition, as shown by Figures 4(e) and $4(\mathrm{f})$, the size of the pits is also increased significantly as a function of Mn content in substrate. This is due to the increase of the size and occurrence of intermetallic particles as the Mn content increases. This is in good consistence with what we observed from Figures 1(a) to $1(\mathrm{f})$ in which the intermetallic particles size and occurrence increase with the Mn content. Cracks and flaws are also caused by these intermetallic particles, as can be seen in Figures 4(e) and $4(\mathrm{f})$, which are mainly due to the difference of volume expansion that is associated with the formation of PAA from aluminium alloy. Hexagonal pores arrangement around the pits is significantly interfered in PAA formed on aluminium substrate with 1.5 and $2.0 \mathrm{wt} \% \mathrm{Mn}$. 


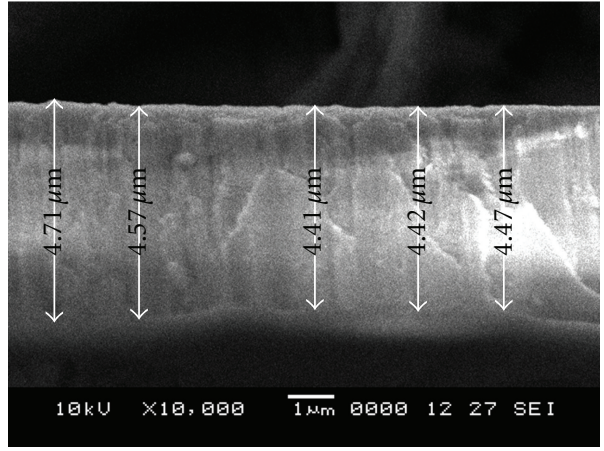

(a)

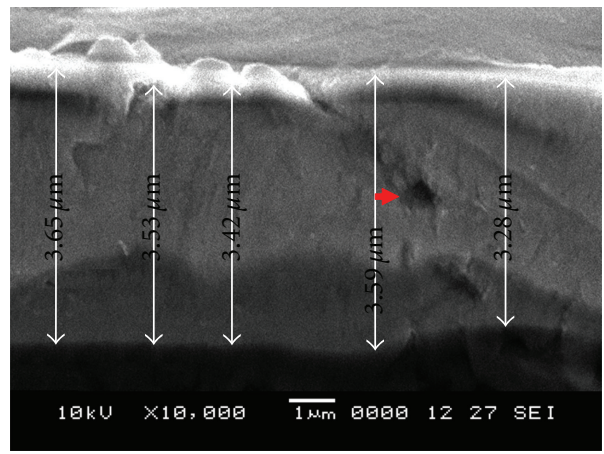

(c)

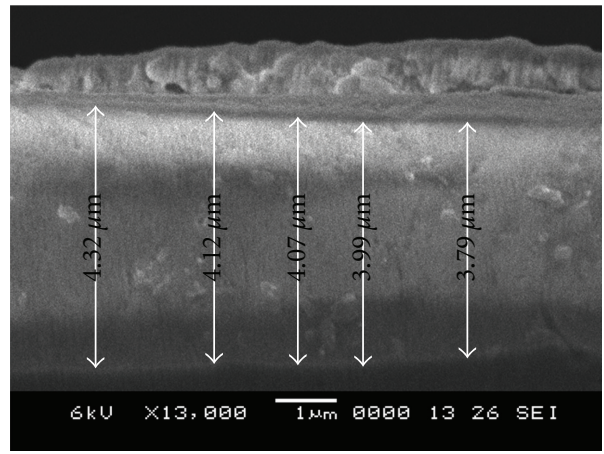

(b)

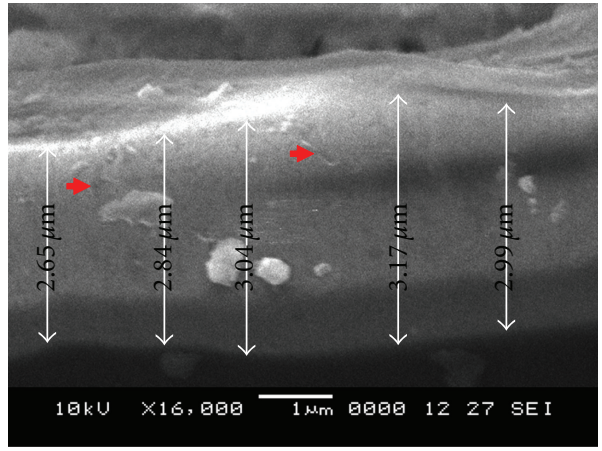

(d)

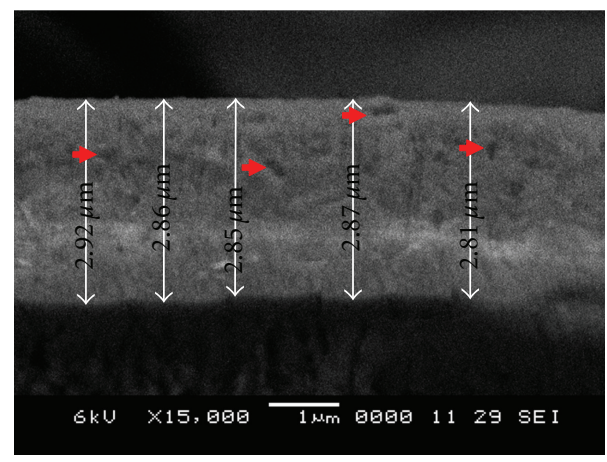

(e)

FIgure 6: Cross-sectional SEM images of anodized substrates of (a) high-purity aluminium, (b) Al-0.5 wt\% Mn, (c) Al-1.0 wt\% Mn, (d) $\mathrm{Al}-1.5 \mathrm{wt} \% \mathrm{Mn}$, and (e) Al-2.0 wt $\% \mathrm{Mn}$.

Pore diameter and interpore distance are two important characteristics that define the applications of PAA. The pore diameter and interpore distance for PAA formed on each substrate were measured and presented in Figure 5. We observed that smaller pores were formed for Al-Mn substrate. Although the relationship is not linear, we observed that the pore diameter decreases as the Mn content increases in the substrate. Similar to pore diameter, the interpore distance also decreases with the increasing Mn content of substrate, although to a smaller extent. We believed that the variation of pore diameter and interpore distance are attributed to the enrichment of Mn species at the oxide/metal interface. It is well known that the oxide grows at the oxide/metal interface. The distribution of electric field at this interface will determine the nucleation sites of the pores and subsequently define the pore diameter and interpore distance. The enrichment of Mn species in the oxide/metal interface changed the properties of the interface and influenced the field distribution at this interface. Thus, the pore diameter and interpore distance varied substantially with the Mn content in the substrate. The mechanism that causes this variation is still under studied.

Thickness of PAA is an indication of the growth rate of the oxide film. It is important to control the thickness of the PAA to grow nanostructured materials of specific length. Figure 6 shows the micrographs of cross-sections of PAA formed on substrates of different Mn content. The average thicknesses of the PAA were plotted in Figure 7. In general, the thickness of PAA formed at same operating conditions decreased as a function of $\mathrm{Mn}$ content in the substrate. 


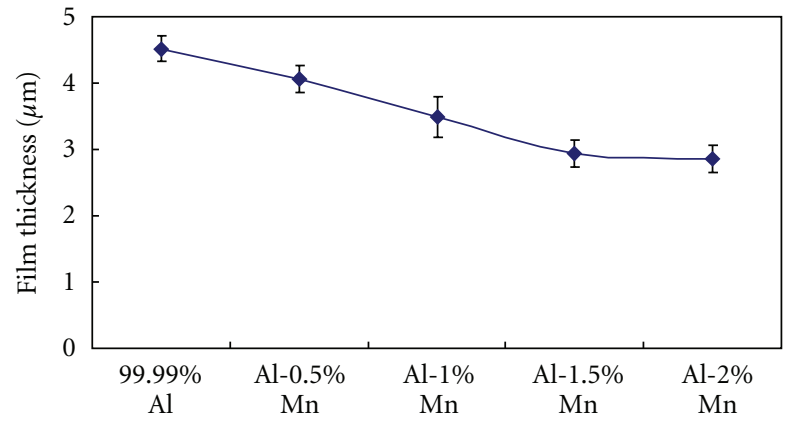

FIgURE 7: Thickness of PAA as a function of Mn content.

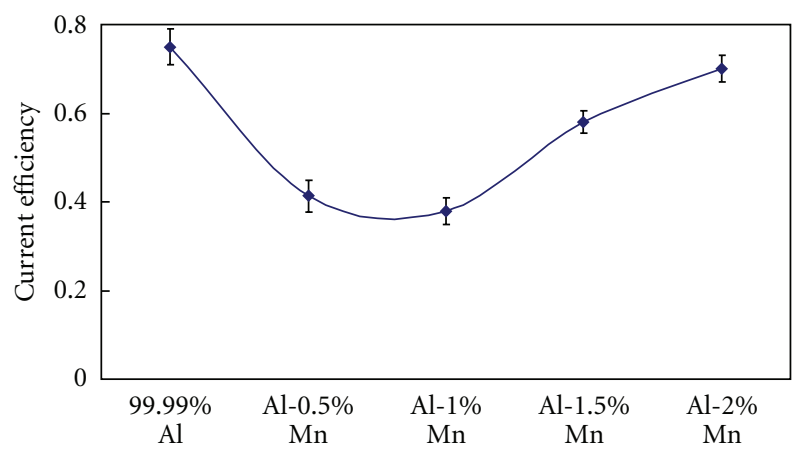

Figure 8: Current efficiency of anodizing process as a function of Mn content.

This observation is in good consistency with the trend of recorded current density as a function of $\mathrm{Mn}$ content in the substrate, as shown in Figure 2. As explained above, we believed that the reduction of PAA thickness with the Mn content of substrate was attributed to the enrichment of $\mathrm{Mn}$ species at the metal/oxide interface. However, the thickness of PAA does not decrease linearly with the Mn content. The thickness of PAA film decreased significantly, when the Mn content increased from high-purity aluminium up to $1.0 \mathrm{wt} \% \mathrm{Mn}$. When the Mn content further increased from $1.5 \mathrm{wt} \%$ to $2.0 \mathrm{wt} \%$, the thickness of PAA film decreased to a lesser extend. We also observed the changes of integrity of PAA film as the Mn content increased. The PAA formed on high-purity aluminium substrate and $\mathrm{Al}-0.5 \% \mathrm{Mn}$ substrate has parallel pores that are normal to the metal/oxide interface. No void or secondary phase was observed in the PAA cross-section of these substrates. For substrates with Mn content greater than $1.0 \mathrm{wt} \%$, voids are present in the PAA film, indicated by red arrows in the micrographs. The occurrence of these voids or secondary phases increases with the content of $\mathrm{Mn}$ in the substrate.

The calculated current efficiencies of the anodizing of respective substrate are shown in Figure 8. We noticed that the high-purity aluminium substrate has the highest current efficiency. The current efficiencies of the anodizing process decreases as the Mn content in the substrate increases up to $1.0 \mathrm{wt} \%$. Above $1.0 \mathrm{wt} \%$, the current efficiencies rise and for substrate with $2.0 \mathrm{wt} \% \mathrm{Mn}$, the current efficiency is almost

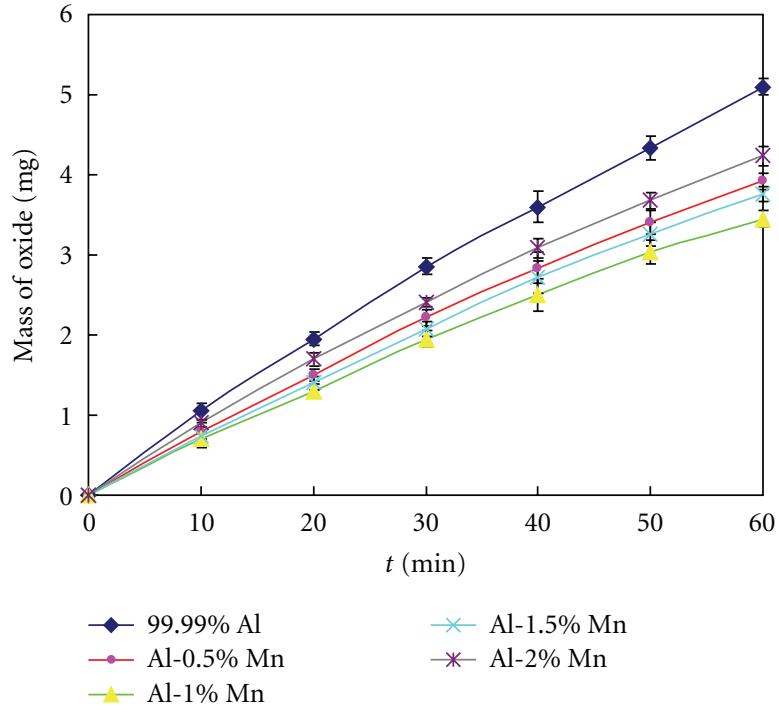

FIgure 9: Oxide mass of PAA formed on various substrates as a function of time.

on par with the current efficiency of the anodizing of highpurity aluminium substrate. The observation is inconsistent with the reduction of thickness of PAA with the increasing Mn content in the substrate, as shown in Figure 6. According to Figure 6, the current efficiency of the anodizing process should decrease as a function of Mn content. Combining with the micrographs in Figure 1 and anodizing behaviour in Figure 2, we explained this trend by the presence of the precipitated phases in the Al-Mn substrate. When the Mn content in the substrate increases up to $1.0 \mathrm{wt} \%$, the current efficiencies decrease, as expected by considering the reduced current density versus time plots in Figure 3. We believed that this is attributed to the enrichment of Mn species at the oxide/metal interface and this reduces the $\mathrm{Al}$ availability for the formation of oxide. However, when the Mn content increases up to $2 \mathrm{wt} \%$, the current efficiencies increases, and this is contradictive to the reduced thickness and current density with the Mn content. We believed this inconsistency to be originated from the presence of secondary precipitates in the PAA. These precipitates have either low or no solubility in the electrolyte and therefore, low or no mass loss at these areas during the anodizing process. As a result, the current efficiencies increase when the $\mathrm{Mn}$ content increases from $1.0 \mathrm{wt} \%$ to $2.0 \mathrm{wt} \%$.

To cross-check the influence of Mn content on the current efficiency of the anodizing process, the mass of PAA on various substrates were plotted against anodizing duration. Figure 9 shows the change of mass of oxide as a function of anodizing duration for $\mathrm{Al}$ substrates of different Mn content. In general, we observed that the mass of oxide increased as a function of anodizing duration. The relation between the oxide mass gain rate and the anodizing duration is closed to a linear one. This indicated that the oxide grows at an almost constant rate during anodizing process. Similar to the current efficiency, we noticed that the high-purity aluminium substrate has the highest rate of oxide mass gain 
and the rate of oxide mass gain also shows the same trend as the current efficiencies. We thus confirmed that the presence of secondary phases in the starting material of Mn content is responsible for the higher oxide mass gain of $\mathrm{Al}-1.5 \% \mathrm{Mn}$ and $\mathrm{Al}-2.0 \% \mathrm{Mn}$.

\section{Conclusion}

The presence of Mn content in the aluminium substrates, although in a small portion, affects the anodizing behaviour and microstructure of PAA and the current efficiency of the anodizing process. The steady-state current density decreased with the increasing $\mathrm{Mn}$ content in the $\mathrm{Al}$ substrates. Addition of $\mathrm{Mn}$ above $1.0 \mathrm{wt} \%$ reduces the uniformity of the structure of PAA and leads to the presence of embedded secondary precipitates in the PAA. Embedded secondary precipitates induce the formation of cracks in the PAA formed on Al-2.0 wt $\%$ Mn substrate. The pore diameter decreases significantly while interpore distance shows little change with the addition of $\mathrm{Mn}$ species. The thickness growth rate of PAA decreases with the addition of Mn. Current efficiency of anodizing of Al-Mn alloys decreased with the addition of $\mathrm{Mn}$ up to $1 \mathrm{wt} \%$ and increased when the $\mathrm{Mn}$ content increases from $1.0 \mathrm{wt} \%$ to $2.0 \mathrm{wt} \%$. This is attributed to the presence of secondary precipitates in the PAA which have either low or no solubility in the electrolyte led to low or no mass loss during the anodizing process. This also explained the reason behind the increasing rate of increase of oxide mass with the Mn content.

\section{References}

[1] F. Keller, M. S. Hunter, and D. L. Robinson, "Structural features of oxide coatings on aluminum," Journal of The Electrochemical Society, vol. 100, pp. 411-419, 1953.

[2] C. C. Lin and C. L. Yang, "Carbon nanotubes grown on nanoporous alumina templates/aluminum foil for electrodes of aluminum electrolytic capacitors," Journal of the Electrochemical Society, vol. 157, no. 2, pp. A237-A241, 2010.

[3] Y. C. Sui, J. A. González-Leon, A. Bermúdez, and J. M. Saniger, "Synthesis of multi branched carbon nanotubes in porous anodic aluminum oxide template," Carbon, vol. 39, no. 11, pp. 1709-1715, 2001.

[4] Z. Chen, Y. Lei, H. G. Chew, L. W. Teo, W. K. Choi, and W. K. Chim, "Synthesis of germanium nanodots on silicon using an anodic alumina membrane mask," Journal of Crystal Growth, vol. 268, no. 3-4, pp. 560-563, 2004.

[5] A. Li, S. Pan, X. Dou et al., "Direct electrodeposition of $\mathrm{ZnO}$ nanotube arrays in anodic alumina membranes," Journal of Physical Chemistry C, vol. 111, no. 20, pp. 7288-7291, 2007.

[6] S. H. Jeong, H. Y. Hwang, S. K. Hwang, and K. H. Lee, "Carbon nanotubes based on anodic aluminum oxide nano-template," Carbon, vol. 42, no. 10, pp. 2073-2080, 2004.

[7] A. Belwalkar, E. Grasing, W. Van Geertruyden, Z. Huang, and W. Z. Misiolek, "Effect of processing parameters on pore structure and thickness of anodic aluminum oxide (AAO) tubular membranes," Journal of Membrane Science, vol. 319, no. 1-2, pp. 192-198, 2008.

[8] S. Ono and N. Masuko, "Evaluation of pore diameter of anodic porous films formed on aluminum," Surface and Coatings Technology, vol. 169-170, pp. 139-142, 2003.
[9] X. Qu, J. Dai, J. Tian et al., "Syntheses of $\mathrm{Nd}_{2} \mathrm{O}_{3}$ nanowires through sol-gel process assisted with porous anodic aluminum oxide (AAO) template," Journal of Alloys and Compounds, vol. 469, no. 1-2, pp. 332-335, 2009.

[10] Y. Zhao, M. Chen, X. Liu, T. Xu, and W. Liu, "Electrochemical synthesis of polydiphenylamine nanofibrils through AAO template," Materials Chemistry and Physics, vol. 91, no. 2-3, pp. 518-523, 2005.

[11] H. Masuda and K. Fukuda, "Ordered metal nanohole arrays made by a two-step replication of honeycomb structures of anodic alumina," Science, vol. 268, no. 5216, pp. 1466-1468, 1995.

[12] J. Choi, K. Nielsch, M. Reiche, R. B. Wehrspohn, and U. Gösele, "Fabrication of monodomain alumina pore arrays with an interpore distance smaller than the lattice constant of the imprint stamp," Journal of Vacuum Science and Technology B, vol. 21, no. 2, pp. 763-766, 2003.

[13] N. Kwon, K. Kim, J. Heo, and I. Chung, "Fabrication of ordered anodic aluminum oxide with matrix arrays of pores using nanoimprint," Journal of Vacuum Science and Technology A, vol. 27, no. 4, pp. 803-807, 2009.

[14] H. Masuda, H. Asoh, M. Watanabe, K. Nishio, M. Nakao, and T. Tamamura, "Square and triangular nanohole array architectures in anodic alumina," Advanced Materials, vol. 13, no. 3, pp. 189-192, 2001.

[15] C. Y. Liu, A. Datta, and Y. L. Wang, "Ordered anodic alumina nanochannels on focused-ion-beam-prepatterned aluminum surfaces," Applied Physics Letters, vol. 78, no. 1, pp. 120-122, 2001.

[16] G. H. Jeong, S. K. Lim, J. K. Park, D. Lee, B. K. Lee, and S. J. Suh, "Nano-pore arrays of anodic aluminum oxide fabricated using a Cr mask," in Proceedings of the 20th International Microprocesses and Nanotechnology Conference (MNC'07), pp. 192-193, November 2007.

[17] Y.-C. Ha and D. Y. Jeong, "Fast fabrication of a high-aspectratio, self-ordered nanoporous alumina membrane by using high-field anodization," Journal of the Korean Physical Society, vol. 57, no. 61, pp. 1661-1666, 2010.

[18] L. Zaraska, G. D. Sulka, J. Szeremeta, and M. Jaskuła, "Porous anodic alumina formed by anodization of aluminum alloy (AA1050) and high purity aluminum," Electrochimica Acta, vol. 55, no. 14, pp. 4377-4386, 2010.

[19] I. Tsangaraki-Kaplanoglou, S. Theohari, T. Dimogerontakis, Y. M. Wang, H. H. Kuo, and S. Kia, "Effect of alloy types on the anodizing process of aluminum," Surface and Coatings Technology, vol. 200, no. 8, pp. 2634-2641, 2006.

[20] D. Lo and R. A. Budiman, "Fabrication and characterization of porous anodic alumina films from impure aluminum foils," Journal of the Electrochemical Society, vol. 154, no. 1, pp. C60C66, 2007.

[21] J. P. Dasquet, D. Caillard, E. Conforto, J. P. Bonino, and R. Bes, "Investigation of the anodic oxide layer on 1050 and 2024T3 aluminum alloys by electron microscopy and electrochemical impedance spectroscopy," Thin Solid Films, vol. 371, no. 1, pp. 183-190, 2000.

[22] A. C. Crossland, G. E. Thompson, C. J. E. Smith, H. Habazaki, K. Shimizu, and P. Skeldon, "Formation of manganese-rich layers during anodizing of Al-Mn alloys," Corrosion Science, vol. 41, no. 10, pp. 2053-2069, 1999.

[23] A. T. Shawaqfeh, Fabrication and Characterization of Novel Anodic Alumina Membranes, Clarkson University, New York, NY, USA, 1997. 
[24] A. J. McAlister and J. L. Murray, "The (Al-Mn) AluminumManganese system," Journal of Phase Equilibria, vol. 8, no. 5, pp. 438-447, 1987.

[25] N. Wang, W. Zhang, J. Xu et al., "Initial stage of pore formation process in anodic aluminum oxide template," Journal of Solid State Electrochemistry, vol. 14, no. 8, pp. 1377-1382, 2010.

[26] J. P. O'Sullivan and G. C. Wood, “The morphology and mechanism of formation of porous anodic films on aluminium," Proceedings of the Royal Society of London, vol. 317, pp. 511543, 1970.

[27] J. M. Montero-Moreno, M. Sarret, and C. Müller, "Selfordered porous alumina by two-step anodizing at constant current: behaviour and evolution of the structure," Microporous and Mesoporous Materials, vol. 136, no. 1-3, pp. 68-74, 2010. 

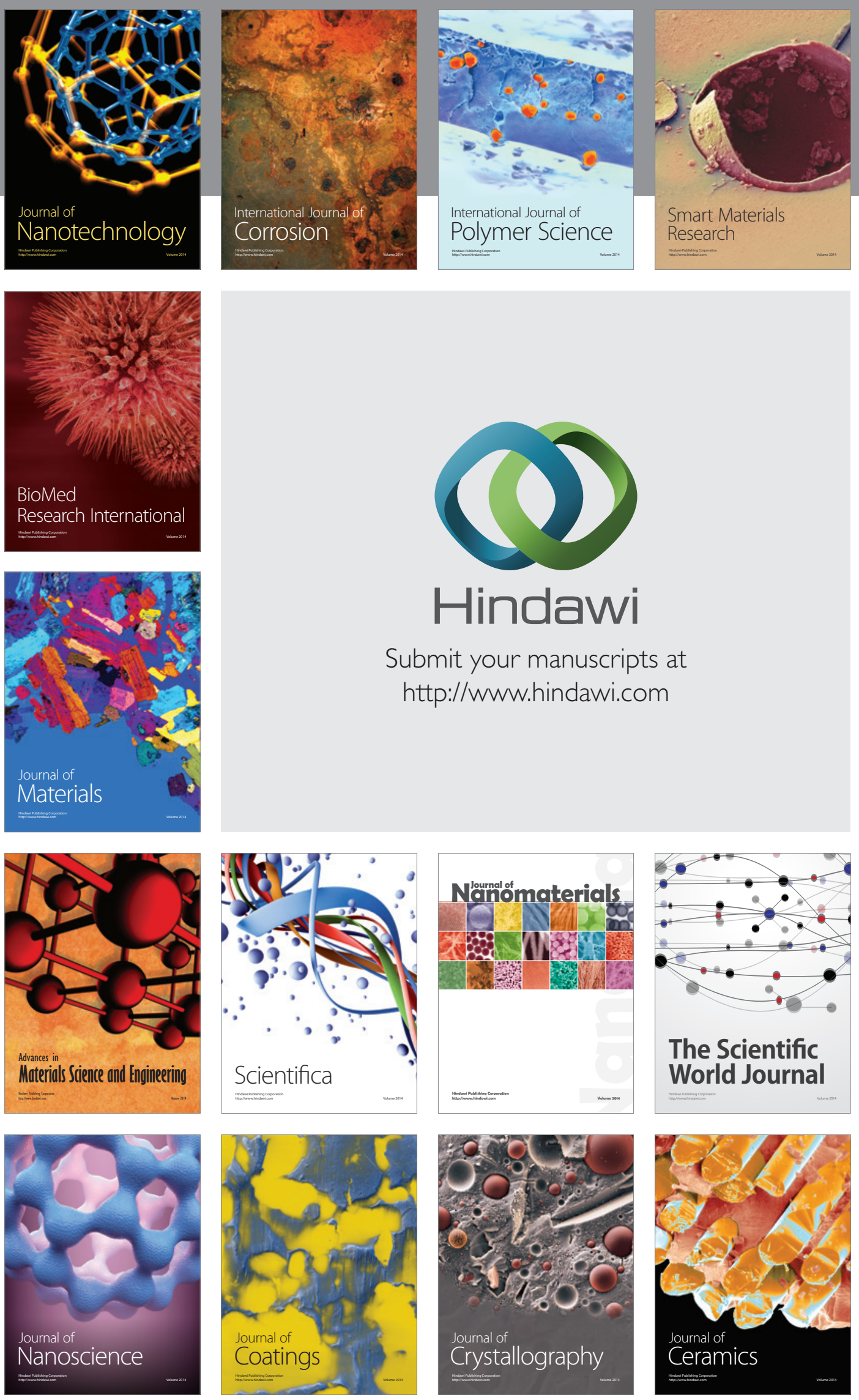

The Scientific World Journal

Submit your manuscripts at

http://www.hindawi.com

\section{World Journal}

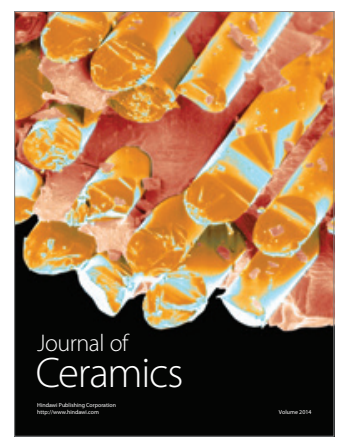

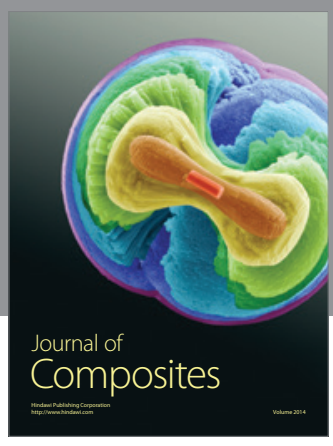
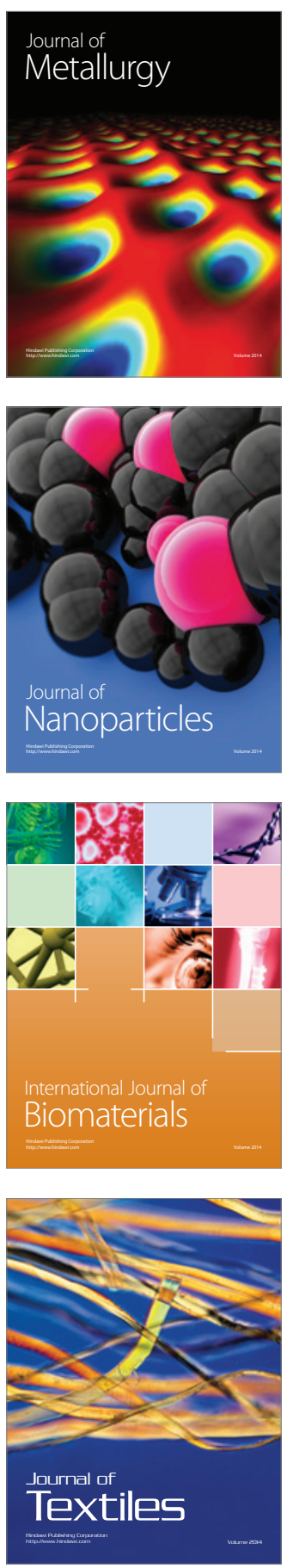